\title{
Nursing and medical students' perceptions of interprofessional education and social interactions: $A$ qualitative study
}

Maryam Alaradi, Maryam Abdulsalam, Khalifa Albenjasim, Omar Ahmed Alwahoush, Salwa Abdulmalek, Wadha

Alsherooqi

Royal College of Surgeons in Ireland Medical University of Bahrain, Bahrain

Received: June 12, 2021

DOI: $10.5430 /$ cns.v9n2p12
Accepted: July 2, 2021

URL: https://doi.org/10.5430/cns.v9n2p12

\begin{abstract}
Objective: Interprofessional education (IPE) is becoming increasingly popular and highly recommended for inclusion in curricula for healthcare professionals. Implementing IPE may improve students' knowledge, skills, and attitudes toward collaborative teamwork, thereby improving health services and health outcomes for patients. This work aimed to explore nursing and medical students' perceptions of IPE and social interactions.

Methods: A qualitative study was conducted using a purposive sample of eight nursing and medical students. Data were collected via two semi-structured focus-group sessions and were analyzed using inductive thematic analysis.

Results: Five main themes and seven subthemes emerged. The main themes were (1) IPE meaning, (2) IPE barriers, (3) IPE facilitators, (4) social interactions, and (5) bridging gaps in students' perspectives. We found that students from both schools had a clear understanding of the definition and importance of IPE. Students reported that lack of interaction is an issue that they have never attempted to address. Students highlighted that IPE enhances IP collaboration and teamwork.

Conclusions: Teaching students about IP communication and professional roles and involving students in joint sessions prepare them for a promising future of high-quality patient care.
\end{abstract}

Key Words: Interprofessional education, Medical students, Nursing students, Healthcare professionals, Social interaction

\section{INTRODUCTION}

The complexity of the healthcare system and the challenges facing healthcare sectors call for innovative approaches to foster improvement. ${ }^{[1]}$ To provide optimal health services to the community, collaborative practice is important and can be accomplished through interprofessional education (IPE). ${ }^{[1]}$ IPE, or interprofessional learning (IPL), occurs when two or more professionals learn with, from, and about each other, aiming to provide competent patient care through improving collaboration and teamwork. ${ }^{[2]}$ IPE is becoming increasingly popular and highly recommended for inclusion in curricula for healthcare professionals, be it in the classroom, in a simulation setting, or during clinical training. ${ }^{[3-5]}$

IPE can create positive outcomes by improving students' knowledge, skills, and attitudes toward collaborative teamwork, highly influencing patients' outcomes. Poor patient outcomes, delayed treatments, misdiagnoses, medication errors, patient injuries, and deaths may be caused by ineffective communication among healthcare providers. ${ }^{[6]}$ Several studies have reported that IPE can cause positive outcomes

\footnotetext{
*Correspondence: Maryam Alaradi; Email: malaradi@rcsi.com; Address: Royal College of Surgeons in Ireland Medical University of Bahrain,
} Bahrain. 
in improving students' knowledge, skills, and attitudes toward collaborative teamwork. ${ }^{[2,7]}$ According to Lennen and Miller, ${ }^{[8]}$ "The American Association of Colleges of Nursing, the Institute of Medicine, and the National League of Nursing have prioritized IP collaboration as a crucial component of education necessary to improve the quality of healthcare in the United States."

Canada and the UK have clearly stated a policy and provided government funding to incorporate IPE into education for health professionals. This initiative is due to the inverse relation between IP collaboration and preventable errors. As a result, IPE is considered a mandatory requirement for preregistration training in healthcare. ${ }^{[9]}$

Those who experience IPE explore the real meaning of teamwork in the clinical setting and feel equity with other members, unlike the expected "traditional hierarchical" interaction. ${ }^{[9,10]}$ Simulating IP communication has a beneficial effect on building communication skills and shaping the "mental model for mutual understanding", and nurses, doctors, and students appreciate and value the training. ${ }^{[11]}$

IPE can be the path toward fostering specific competencies such as teamwork, leadership, consensus building, and the ability to identify patient goals. ${ }^{[12]}$ University-based IPE can enhance students' attitudes toward professional collaboration and the decision-making process and ease communication among health professionals, improving patient safety and decreasing errors. ${ }^{[9]}$

Implementation of IPE in higher education can be facilitated by a mutual understanding of IPE, development of IPE "thinking and acting", exchange of knowledge, shared knowledge, and skilled and enthusiastic facilitators. ${ }^{[5,13]}$ However, several barriers that impede the implementation of IPE were also reported. Lack of opportunity and conflict in school schedules, curriculum structure, lack of financial support, lack of faculty-development initiatives, and high workload (including teaching and administrative tasks) were reported as hindering factors. ${ }^{[13,14]}$

Worldwide, a plethora of research studies has been done on IPE. However, in the Gulf Cooperation Council Countries (GCC), a few studies have been conducted in Saudi Arabia, Qatar, and Kuwait. ${ }^{[4,15-18]}$ Most of the studies employed quantitative approaches. In Bahrain, no study is known to have been done on IPE. This research study was one of the university's IPE initiatives that aimed to explore nursing and medical students' perceptions of IPE and social interactions.

\section{MATERIALS AND METHODS}

\subsection{Design}

This study employed a qualitative approach to explore nursing and medical students' perceptions of IPE and social in- teractions.

\subsection{Sample and sampling}

We recruited five nursing and three medical students $(\mathrm{N}=$ 8) using purposive sampling. To ensure that participants had sufficient experience with student life at the university, participants were included in the study if they were nursing or medical students who had attended for at least two years.

\subsection{Data collection}

All students were approached through emails sent by the university's Marketing and Communication Office. Research flyers-which included the research title, aim, and volunteering opportunities — were distributed around the campus. Interested students contacted the researchers through emails. Initially, we recruited twelve medical and nursing students, but one nursing student and three medical students opted out of participating in the focus-group sessions.

We developed a semi-structured questionnaire to guide the focus-group sessions. Students from the same school tend to feel more comfortable expressing their opinions freely in front of each other; therefore, one focus-group session was held for each school. Each focus group was audiotaped and lasted 60 to 90 minutes. Participants also completed a short demographic questionnaire about age, gender, nationality, school, and program year.

\subsection{Data analysis}

We employed an inductive thematic analysis approach based on Braun and Clarke ${ }^{[19]}$ thematic analysis phases. First, the recordings were transcribed verbatim; researchers read through the text and took notes. Second, similar statements were highlighted and converted into codes. Next, the codes were collapsed into major themes. Forth, the emergent themes were reviewed and named, and finally the report was generated.

\subsection{Trustworthiness}

We followed the four trustworthiness criteria (credibility, transferability, dependability, and confirmability) developed by Lincoln and Guba. ${ }^{[20]}$ Nursing and medical students conducted the focus group sessions which ensured prolonged engagements with the participants and persistent observation. In addition, the transcripts of the recordings were reviewed and verified by the participants which fulfilled the member check criteria. To ensure investigator triangulation, the focus group sessions were conducted by the research team members and the transcriptions were analyzed independently and then reviewed and compared by all the researchers. The authors provided a detailed description of the research method 
which may aid in the transferability of the research. Dependability and confirmability were ensured through maintaining research records, notes, and meetings minutes.

\subsection{Ethical considerations}

The university's Research Ethics Committee approved the study. Informed consent was obtained after researchers provided information about the research and its purpose. Participation was voluntary.

\section{Results}

A total of eight students (five nursing and three medical) participated in this study in two separate focus-group discussions. All participants were Bahraini and between ages 19 and 24 .

Five main themes emerged: (1) IPE concept, (2) IPE barriers, (3) IPE facilitators, (4) social interactions, and (5) bridging the gap in students' perspectives (see Table 1).

Table 1. Interprofessional education themes and subthemes

\begin{tabular}{ll}
\hline Themes & Subthemes \\
\hline IPE Concept & IPE meaning \\
& IPE impact on practice \\
IPE Barriers & Personal level \\
& Academic level \\
IPE Facilitators & University programs \\
Social Interaction & \\
Bridging the gap: students' perspectives & Curricular activities \\
\hline
\end{tabular}

\subsection{Theme 1: IPE concept}

\subsubsection{Subtheme 1: IPE meaning}

The participants defined IPE as an interrelated program that involves educating two different professions in a healthcare setting, sharing knowledge and experience, and complementing each other's education.

$\mathrm{P} 2 \mathrm{~N}$ : “Two or more students from different professions in [the] healthcare system sharing their experience and knowledge."

P4N: "Interrelated interaction with the medical students and the nursing students within the campus or even outside of the campus, developing relationships with other students."

P1M: "Two or more professions, like, collaborating on one thing or one aim, like, basically collaborating on, like, to solve or resolve an issue."

Students indicated that working together means complementing each other.

P3M: "But I think that [IPE] should be ... brought forward and approved by having us engage with, for example, the nursing students as well if we're put in teams and expected to complete group work. I think that sort of changes the way things are ... the challenge."

P2N: "The language barrier would be breached, and they will build relationships between each other."

\subsubsection{Subtheme 2: IPE impact on practice}

Nursing and medical students reported that their future careers require collaboration and teamwork to provide quality healthcare services. Medical students highlighted teamwork as the best way to deliver quality patient care. Students believed that IPE would allow them to understand each other's roles better. Medical students defined working with nurses as a "harmonious relationship." However, medical students also expressed concern that they do not experience teamwork or interaction with nurses until graduation.

P2M: "During surgery, like, the nurses know exactly what the doctor wants without them even tell anything, but that develops over years with clinical. So, why not making it developed, like, during the medical school? And then would make life easier and clinical mistakes probably much less."

P3M: "It has to be everyone sort of working around improving the patients' health, and the only way to really do that is to work as a team."

P3N: "From IPE, you can understand the role, how do you think, what we should do, what we shouldn't do with the doctors ... how we'll be dealing with a doctor, with their concept."

Medical students asserted that nurses could bridge the communication gap between medical students and patients, a skill that nurses acquire by spending more time in clinical placements. For example, for some non-Arabic-speaking medical students, the language was a barrier to communica- 
tion with local patients and was considered a doctor-patient barrier. Such students might require help from nurses for translation.

P1M: "We will be unaware of medical terminology in Arabic that especially most of our patients are speaking where the nursing gets used to explaining to patients."

\subsection{Theme 2: IPE barriers for implementation}

In the theme of IPE barriers for implementation, two subthemes emerged: (1) personal-level barriers and (2) academic-level barriers.

\subsubsection{Subtheme 1: Personal-level barriers}

A nursing student described other students from the same school as being stuck in the "high-school atmosphere", where they disregard the usefulness of extracurricular projects such as joining the Research Summer School.

P3N: "Think most of the students here are focused only on their studying. They are not aware of this issue and how we can improve this issue. Nursing students come to university as if it was high school. I attend and leave ... I finish and leave ... Medical students spend more time here in the university."

Many students felt that they must focus on their studies rather than be aware of their surroundings. Some of the nursing students feared that they would not be accepted by others.

P5N: "Nursing students will be a little bit shy to talk with doctors ... Maybe she will not accept me or he will not accept me."

\subsubsection{Subtheme 2: Academic-level barriers}

Because they were already placed in clinical settings, senior nursing students had a greater idea about doctors' roles. On the other hand, medical students reported a lack of understanding of nurses' roles.

P3M: "Unfortunately, we don't have many opportunities to learn about what it is that the nursing students are doing."

Additionally, the lack of awareness of nurses' roles led to underestimating them and considering them at the bottom of the medical hierarchy.

P3M: "Medicine historically has been always sort of hierarchical in a sense that, oh, there are doctors, and then there are people who work under them .... A lot of interns, they underestimate nurses, especially since they just graduate ... Probably some of them will be arrogant and say, Oh, nurses don't know how to do that. But, like, they probably have more knowledge than the new intern, so knowing what nurses can do and can't do is very important."

Published by Sciedu Press
During clinical placement, students recognize each other in clinical settings by the uniform and university logo but tend not to interact.

P2M: “I do recognize, but I don't know them personally, so it just that because they kind of strangers for me, because so I don't know. It sounds better to go and asks senior staff nurse."

P4N: "Whenever I see someone from [the university], a medical student ... oh, [university]."

P3N: "Yes, we are waiting for someone to smile for us back."

Similarly, participants highlighted that they were ignorant of the other school's curricula and programs.

P2N: "Their program is kind of different from ours ... They should involve both students in the history of Bahrain and human rights, the history of Bahrain project ... Nursing school, like, they get into clinical work much earlier than the medical school. So, if a class like that would happen, let's say that ... like, at least the people from, like, nursing year 3 with medical students from IC3 where they have just begun their medicals ... like, mean their clinical studies and a class like that, I think both would benefit ... time management, so it should be structured between nursing and medical students."

Participants reported lack of time and conflict of teaching schedules as barriers for IPE and social interactions between nursing and medical students.

P3M: "Yeah, we do have the curiosity, but, like, we don't really have the need, and we don't really have the time to ... the quantity of information that we need to learn and very quickly. We, um, I guess learn how to sort to determine what we really need to know, and we learn how to ignore everything else."

P3N: "Medical [students are] under pressure all the time, and nursing students also."

P5N: "I don't have the time to know about the medical student."

P1M: "But it is hard to merge the timings for both medical-nursing students ... the nature of the program design or the way the curriculum is designed."

P3M: "Sometimes, the things aren't scheduled in ways that accommodate everyone ... Um, that is definitely one barrier."

\subsubsection{Theme 3: IPE facilitators}

The university has established several programs that the participants perceived as facilitators for IPE. One of the programs is International Community Engagement (ICE). A group of nursing and medical students travel abroad with 
a mentor and practice their professions in a collaborative atmosphere. The program is quite admired for bringing nursing and medical students together and initiating interactions. While spending time together, students bond and work as a team in the hospitals they visit.

P3M: "I've had the opportunity to engage with current nursing students in a professional setting because we traveled as a team and we worked as a team in the hospital we are at, and that really highlighted how much we're really missing out on ... in terms of learning from each other and alongside each other and highlighted how much, how many opportunities there actually are to benefit from [each other].... After having ... had the ICE experience, it really did change the way I perceive the nursing students in the hospital, so it really, I think, improved my perspective on nursing in general."

The Student Council is another university venue where nursing and medical students work together to achieve a joint mission. Participants thought that events, clubs, and societies bring students together even more than meeting students from other clinical placement schools. However, sometimes, it is hard to arrange events that accommodate the academic schedules of both schools.

P1M: "Student Council discusses it in meetings.... There is a segregation between medical students and nursing students. Like, there is no communication. I think every year they address the same issue, and we try ... and whenever we try to impose, like, changes, like, they're accepting the fact, but it is hard to merge the timings for both medical-nursing students.... In the university itself, I think with time, you develop, like, some friendship. Like, probably, you know them from events or societies much more than during clinical setting."

Research Summer School is another opportunity for nursing and medical students to learn together and learn from each other.

P1M: "It depends on the nature of the project.... Like, certain projects, for example, if it's clinical research, that requires surgical knowledge or properly.... For example, if there is a research in basic sciences, I think [that] would be equal to them because I think nursing students could have some knowledge in basic sciences."

\subsection{Theme 4: Social interactions}

When asked how nursing and medical students interact with each other, the participants reported the following.

P3M: "It is like survival. So, that [is] one of the other reasons why I think a lot of the medical students don't engage with really anyone, sort of becoming socially isolated in a sense... As medical students, like, we don't focus on that....
[It] doesn't concern us much now during our studies. Maybe [it] will concern us later in our career 'cause we will have to, like, to interact with nurses and all of that, but, like, during the actual medical years, um, it doesn't really affect us much. We never needed to learn about [each other]."

P1N: "Nursing student, all or most of them are Arab, so the culture, they are, like, shy or something, but the medical student, they are from different cultures from different societies, so they are more open to talking to, share knowledge, so they have the initiative to come to us."

P2N: "Interactions between boys and girls and this kind of making the gap."

\subsection{Theme 5: Bridging the Gap in students' perspectives 3.4.1 Subtheme 1: Curricular activities}

The participants discussed ways to bridge the gap between nursing and medical students. According to participants, nursing and medical students should work on joint case studies during clinical placements and have combined classes on campus.

P3M: "Students could form little groups that go to a different department in the hospitals and maybe have conversations around during experiences there. Taking blood pressure, measuring blood glucose ... are things that I'm sure that the nursing students would definitely be able to sort of helping us along with, and it would definitely be a place ... to sort of start ... engagement. I believe we have some subject sharing together, the same, but we take in different years. We can combine these subjects in one. The college should make one subject for both."

Students believed that the university must provide classes for communication skills between healthcare providers and patients and among healthcare providers themselves to avoid miscommunication.

P3M: "The lab skills, the role of the doctor, and the role of the nurse. We are having nursing students who are playing the role of the doctor. We can have it a doctor, like, a medical student and the nurse student."

"Communication ... it is not just between us and patients, so also between us and the team, that's something that we definitely lack.”

Introducing shared, mandatory sessions would ease interactions and mutually benefit both schools; students would learn together in lectures or clinical rounds. This situation would create great opportunities for cooperation among all students. Medical students complementing the theoretical knowledge of nursing students would allow nursing students to gain specific clinical skills in return. 
P2M: “A class where both would be in the same place would be quite interesting 'cause I think both would benefit 'cause, like, I think a lot of the nursing students would have a lot of clinical experience, but maybe they don't have as much as theoretical background as the medical student."

P1N: "To have a course where the expectations are the same for everyone, the evaluation is the same for everyone.... If we combined medical and nursing students in one session, they will build a relationship between each other, so in the coming years, they will be a friend. They will not [be] afraid to interfere with each other again."

Incorporating nursing and medical students into classes in the current system can be a good step to initiate IPE and social interactions.

P1M: "For example, the Arabic history of Bahrain, these modules, they're taken by both schools. Like, if there was, if they merged the med school and the nursing school within these modules, probably from early on, they're going to be some traction, like, even with modules then in foundation such as the English language if they have in nursing school."

\subsubsection{Subtheme 2: Extracurricular activities}

Students from both schools reported that IPE sessions must start early before the professions begin to diverge. This situation would directly allow students from both schools to interact rather than try to fix poor interaction later.

P3M: "Medical school or nursing are mostly high school graduates, so they are kind of at the same stage, but once I think as we progress along the years, there is sort of this diverge that happens between the two schools... If things start early on ... so the students, when they first come in the school, there is much more flexibility, I think both in time and perspective because, of course, you start acquiring chasing the environment that you're in, and if there is this segregated kind of environment ... the longer you stay in it, the more challenging it becomes to sort of realigning yourself to more synchronized attitude. It is like when you educate children ... rather than you educate adults. Children are much more valuable 'cause they don't have any prior experiences that basing their attitudes."

Nursing and medical students agreed that combining the students from both schools in the orientation program could establish a base for interaction. New friendships would take away the fear of initiating professional interaction.

P1M: "During orientation, there is an icebreaker thing. Medicine do it separately than nursing. If they do it at the beginning for both schools, it will be different, at least getting along to know the nurses more, and they get to us more."

Published by Sciedu Press
P2M: "Early between two schools, I think it would be much easier for them to get along in clinical years and even after when they graduate."

\section{Discussion}

This study aimed to explore nursing and medical students' perceptions of IPE and social interactions. The participants exhibited an understanding of the meaning of IPE, which was evident in the descriptions they used, such as "sharing experience and knowledge", "collaboration to solve problems", "developing relationships", and "complementing each other". These definitions seem to be missing some elements from the IPE definitions in the literature. ${ }^{[21,22]}$ However, the participants highlighted relying on teamwork, understanding each other's roles, reducing medical errors, and improving patients' health as the main impacts of IPE. Our findings were consistent with those of Homeyer et al. ${ }^{[5]}$ in that IPE can enhance communication and cooperation among healthcare providers, thus improving patient care. IPE reduces stereotyping and improves mutual attitudes and understanding of roles. It is worth noting that some medical students still possess the misconception of the nurse as a helper to bridge the gap between medical students and patients, which is not the aim of IPE.

Although participants seemed to define IPE in line with the literature definitions, it is clear from some responses that the focus was on learning each other's roles rather than working with each other on a shared goal. This theme was evident when the participants were asked about barriers to IPE. The participants recognized a lack of knowledge and understanding of the other school's curriculum. Still, the lack was not a concern because students are immersed in their studies, which consume most of their valuable time. The difference in the structure of nursing and medical schools' curricula-specifically the time of involvement in clinical work, which has nursing students involved in clinical practice much earlier than medical students-was reported as a barrier to IPE. Each school has an independent curriculum, learning outcomes, and modules in terms of the education system, and the conflicts in the study schedules may affect the implementation of IPE activities. These barriers were in line with the literature review findings by Sunguya et al. ${ }^{[14]}$

Lack of knowledge about each other's programs is a relatively strong indicator of poor interaction. Another issue that nursing students addressed was difficulty communicating with medical students due to the lack of common topics on personal and professional levels. Students usually begin developing friendships at the start of the academic year, which locks them in their professional groups and makes it harder for the two schools to be combined over time. Early 
attempts to combine students and health professionals create chances to solve the problem and enhance communication. ${ }^{[9]}$ Many nursing students use Arabic as a common language for day-to-day communication; however, medical students prefer English. It seems that students in the early part of the program favor staying in school groups, which leads to different spoken languages, stereotyping, and lack of socialization. ${ }^{[23]}$ Moreover, students may have problems communicating with those from the other school because they might initially experience the feeling of being different. ${ }^{[11]}$

Students strongly believed that establishing an IPE strategy could be the missing link that would finally bridge the gap between the schools of nursing and medicine. Such a strategy would bring the schools together to get students to recognize each other's programs and discuss the pros and cons of each. The essential idea behind having IPE sessions is that nursing students' skills could complement those of medical students because they only acquire them in internship years. Students believed that IPE sessions play an instrumental role in enhancing students' skills and personalities and helping develop relationships.

Students from both schools had similar suggestions to be implemented at the university. The students stated that providing classes is part of the faculty's responsibility and that IPE lectures should be synchronized based on time and financial resources. ${ }^{[13]}$ Participants suggested merging students from both schools into some modules that already exist in the curricula.

Part of the university's responsibility is to provide united training sessions to ensure IPE delivery to a large number of students from both schools. A study emphasized that for IPE to be successful, the training programs must consider harmonizing nursing and medical curricula. ${ }^{[13]}$ Updated strategies and training to maintain the major integration of IPE into academic and clinical settings are vital. ${ }^{[9]}$

Case studies and simulations play a significant role in building relationships based on interchangeable skills and mutual respect's jobs. Involving students in decision-making during case studies stimulates discussion, thereby encouraging students to present various approaches to patient care. ${ }^{[1]} \mathrm{A}$ good application of the IPE strategy includes simulating clin- ical experience, a session that would enhance communication and analyze responsibilities in a patient-care setting.

\section{Limitations}

There were a few limitations that we faced while conducting this research. One of the limitations was recruiting nursing and medical students to participate in the focus groups. Recruitment included only local students because most of the international students were on summer vacation and therefore unavailable. Due to the scarcity of available students, some participants were approached personally and asked to volunteer. The inclusion of international students with various cultural backgrounds might have further enriched our findings. Although the focus groups' sample size was small, saturation was nevertheless reached.

\section{Conclusions}

We explored nursing and medical students' perceptions of the facilitators and barriers of IPE sessions. Students highlighted that IPE enhances IP collaboration and teamwork. Teaching students about IP communication and professional roles and involving students in joint practice prepares them for a promising future of high-quality patient care.

IPE is based on mutual benefits. It can promote mutual respect and understanding, which can overcome the issue of stereotyping. It was impressive that the participants showed interest and willingness to join IPE sessions. For future implementation, the university should consider the distinct curricula of the two different programs and work on finding common ground to establish IPE sessions and activities. Involving students in decision-making and choosing the solutions and themes of IPE are the best ways to enhance confidence and interest to excel.

\section{FUNDING}

This research was funded by RCSI-MUB Research Summer School. The funding organization had no role in the collection, analysis, or interpretation of the data or the preparation and approval of the manuscript.

\section{Conflicts OF INTEREST Disclosure}

The authors declare they have no conflicts of interest.

\section{REFERENCES}

[1] Health Professions Networks Nursing \& Midwifery Human Resources for Health. Framework for Action on Interprofessional Education \& Collaborative Practice. World Health Organization. 2010. Available from: http://apps.who.int/iris/bitstrea $\mathrm{m} / \mathrm{handle} / 10665 / 70185 / \mathrm{WHO}$ HRH_HPN_10.3_eng.pdf ; jses sionid=4A34AE4A3C137206A264A7CB5EB21E04? sequence $=1$

[2] Guayana S, Barr H. The effectiveness of interprofessional education in healthcare: A systematic review and meta-analysis.The Kaohsiung Journal of Medical Science. 2018; 34(3): 160-165. PMid: 29475463. 
https://doi.org/10.1016/j.kjms.2017.12.009

[3] Anderson E. Evaluating interprofessional education: An important step to improving practice and influencing policy. Journal of Taibah University Medical Sciences. 2016; 11(6): 571-578. https : //doi.org/10.1016/j.jtumed.2016.08.012

[4] El-Awaisi A, Anderson E, Barr H, et al. Important steps for introducing interprofessional education into health professional education. Journal of Taibah University Medical Sciences. 2016; 11(6): 546-551. https://doi.org/10.1016/j.jtumed.2016.09.004

[5] Homeyer S, Hoffmann W, Hingst P, et al. Effects of interprofessional education for medical and nursing students: enablers, barriers, and expectations for optimizing future interprofessional collaboration - a qualitative study. BMC Nursing. 2018; 17(13): 1-10. PMid: 29643742. https ://doi.org/10.1186/s12912-018-0279-x

[6] Foronda C, Macwilliams B, McArthur E. Interprofessional communication in healthcare: An integrative review. Nurse Education Today. 2018; 19: 36-40. PMid: 27428690. https ://doi .org/10.1016/ j.nepr. 2016.04 .005

[7] Marion CE, Balfe LM. Potential advantages of interprofessional care in rheumatoid arthritis. Journal of Managed Care Pharmacy. 2011; 17(9Suppl B): S25-S29. PMid: 22073937. https : //doi .org/10 .18553/jmcp. 2011.17.s9-b.S25

[8] Lennen N, Miller B. Introducing Interprofessional Education in Nursing Curricula. Teaching and Learning in Nursing. 2017; 12(1): 59-61. https://doi.org/10.1016/j.teln.2016.07.002

[9] Lapkin S, Levett-Jones T, Gilligan C. A systematic review of the effectiveness of interprofessional education in health professional programs. Nurse Education Today. 2013; 33(2): 90-102. PMid: 22196075. https://doi.org/10.1016/j.nedt.2011.11.006

[10] Lim D, Noble-Jones R. Interprofessional education (IPE) in clinical practice for preregistration nursing students: A structured literature review. Nurse Education Today. 2018; 68: 218-225. PMid: 29966884. https://doi.org/10.1016/j.nedt.2018.06.020

[11] Frenk J, Chen L, Bhutta ZA, et al. Health professionals for a new century: transforming education to strengthen health systems in an interdependent world. The Lancet. 2010; 376(9756): 1923-1958. https://doi.org/10.1016/S0140-6736(10)61854-5

[12] Scherer Y, Myers J, O'Connor T, et al. Interprofessional Simulation to Foster Collaboration between Nursing and Medical Students. Clinical Simulation in Nursing. 2012; 9(11): e497-e505. https://doi.org/10.1016/j.ecns.2013.03.001

[13] Lawlis TR, Anson J, Greenfield D. Barriers and enablers that influence sustainable interprofessional education: A literature review. Journal of Interprofessional Care. 2014; 28(4): 305-10. PMid: 24625198. https://doi.org/10.3109/13561820.2014.8959 77
[14] Sunguya BF, Hinthong W, Jimba M, et al. Interprofessional education for whom? - Challenges and lessons learned from its implementation in developed countries and their application to developing countries: A systematic review. PLOS ONE. 2014; 9(5): e96724. PMid: 24809509. https://doi.org/10.1371/journa 1. pone.0096724

[15] Al-Eisa E, Alderaa A, AlSayyad A, et al. The perceptions and readiness toward interprofessional education among female undergraduate healthcare students at King Saud University. The Journal of Physical Therapy Sciences. 2016; 28(4): 1142-1146. PMid: 27190442. https://doi.org/10.1589/jpts.28.1142

[16] AlAhmari M. Interprofessional Education: Saudi Health Students' Attitudes Toward Shared Learning. Advances in Medical Education and Practice. 2019; 10: 1061-1067. PMid: 31908564. https : //doi.org/10.2147/AMEP.S226477

[17] Fallatah HI, Jabbad R, Fallatah HK. Interprofessional Education as a Need: The Perception of Medical, Nursing Students and Graduates of Medical College at King Abdulaziz University. Creative Education. 2015; 6(2): 248-254. https://doi.org/10.4236/ce.2015.62 023

[18] Katoue MG, Awad AI, AL-Jarallah A, et al. Medical and pharmacy students' attitudes towards physician-pharmacist collaboration in Kuwait. Pharmacy Practice. 2017; 15(3): 1029. PMid: 28943986. https://doi.org/10.18549/PharmPract.2017.03.1029

[19] Braun V, Clarke V. Using thematic analysis in psychology. Qualitative Research in Psychology. 2006; 3(2): 77-101. https ://doi .or g/10.1191/1478088706qp063oa

[20] Korstjens I, Moser A. Series: Practical guidance to qualitative research. Part 4: Trustworthiness and publishing. European Journal of General Practice. 2018; 24(1): 120-124. PMid: 29202616. https ://doi.org/10.1080/13814788.2017.1375092

[21] Buring SM, Bhushan A, Broeseker A, et al. Interprofessional education: definitions, student competencies, and guidelines for implementation. American Journal of Pharmaceutical Education. 2009; 73(4): 1-8. PMid: 19657492. https ://doi.org/10.5688/aj730459

[22] Reeves S, Perrier L, Goldman J, et al. Interprofessional education: effects on professional practice and healthcare outcomes. Cochrane Database of Systematic Reviews. 2013; 28(3): CD002213. PMid: 23543515. https://doi.org/10.1002/14651858.CD0 02213. pub3

[23] Mahler C, Schwarzbeck V, Mink J, et al. Students' perception of interprofessional education in the bachelor program "Interprofessional Health Care" in Heidelberg, Germany: An exploratory case study. BMC Medical Education. 2018; 18(19): 181-8. PMid: 29370784. https : //doi .org/10.1186/s12909-018-1124-3 